\title{
Desenvolvimento, alternativas de/ao desenvolvimento e a questão ambiental
}

\author{
Desarrollo, alternativas de o al desarrollo y la cuestion ambiental \\ Development, alternatives to / development and the environmental issue
}

\author{
Cristiane Coradin ${ }^{1}$
}

\begin{abstract}
Resumo
O desenvolvimento como crescimento econômico tem sido promovido por países ditos "desenvolvidos" como uma utopia a ser alcançada pelos países do sul, jamais alcançado. A questão ambiental emerge em contextos de crise desse modelo socioeconômico hegemônico e mediante tendências ao esgotamento dos recursos naturais em idos de 1970. As propostas apresentadas e assimiladas pela ONU e pela perspectiva hegemônica de desenvolvimento tem se mostrado insuficientes, mediante contextos de ampliação de desigualdades sociais, econômicas, culturais e políticas, e da criação de novos imperialismos, baseados em economias neoextrativistas, notadamente desde o sul. Esses contextos tem propiciado a emergência de teses alternativas de e ao desenvolvimento, envolvendo também a questão ambiental. O presente artigo é um estudo teórico, realizado através de revisão de literatura, e tem como objetivo discorrer e dialogar com as principais teses de desenvolvimento presentes na América Latina, contextualizando o modelo hegemônico, suas insuficiências, bem como dialogar com as propostas alternativas que foram e vem sendo construídas e assimiladas ao longo desse tempo, principalmente aquelas provindas desde olhares epistêmicos do sul, problematizando esse tema com a emergência e capacidade de resposta desses horizontes alternativos à questão ambiental.
\end{abstract}

Palavras chave: desenvolvimento; meio ambiente; alternatividades

\section{Resumen}

El desarrollo como crecimiento económico ha sido buscado y difundido a través de los países llamados "desarrollados" como una utopia para ser alcanzada por el Sur, jamás alcanzada. La cuestión ambiental surge en contextos precarios y tendencias al agotamiento de los recursos naturales en Gone 1970. Las propuestas apresentadas y asimiladas por la ONU y la perspectiva hegemónica de desarrollo, ya que se ha demostrado ser insuficiente mediante la creación de nuevos imperialismos contextos, sobre la base de neoextrativistas economías, especialmente desde el sur. Estos contextos há proporcionado a emergência de tesis alternativas de del desarrollo. El presente articulo es produto de uma revision de literatura e tiene como objetivo discutir com las principales tesis del desarrollo presente em estos contextos, contextualizar el modelo hegemónico, sus insuficiencias, así como el diálogo con las propuestas alternativas que se estan construyendo y siendo asimiladas durante ese tiempo, en particular las originadas desde las miradas del sur, y la discusión de este tema con la emergencia y capacidad de respuesta de estas miradas alternativas a las cuestiones ambientales.

Palabras clave: desarrollo; medio ambiente; alternatividades

1 (Mestre em Extensão Rural; Universidade Federal do Paraná; Curitiba, Paraná, Brasil; cristianemottimcoradin@gmail.com. Trabalho apresentado no I Seminário Latino-Americano de Estudos em Cultura - SEMLACult - ST 11 - Bem Viver e ecossocioeconomia como alternativas de desenvolvimento, Foz do Iguaçu/PR, Brasil, 2017). 


\begin{abstract}
Development as economic growth has been sought and disseminated via so-called "developed" countries as a myth to be reached by the countries of the South, never reached. The environmental issue emerges in the contexts of precariousness and tendencies to the exhaustion of natural resources in the 1970s. The proposals presented and assimilated by the $U N$ and the hegemonic perspective of development have since proved insufficient through contexts of creation of new imperialisms based on Neo-extractive economies, notably from the south. These contexts have favored the emergence of alternative theses from and to development. The present article is a theoretical study, carried out through literature review, and aims to discuss and dialogue with the main theses of development present in these contexts, contextualizing the hegemonic model, its insufficiencies, as well as dialog with the alternative proposals. Which were being built and assimilated throughout that time, especially those coming from perspectives of the south, problematizing this theme with the emergence and capacity of response of these alternative horizons to the environmental question.
\end{abstract}

Keywords: development; environment; alternatives

\title{
1. Introdução
}

As discussões sobre desenvolvimento emergiram no século $\mathrm{XX}$, em decorrência dos processos de industrialização dos países do norte, e também pela necessidade de compreensão da relação desses fenômenos com a industrialização e urbanização dos países do sul global. Nesses contextos e, mais contemporaneamente, principalmente após a divulgação dos Estudos do Painel Intergovernamental sobre Mudanças Climáticas, o meio ambiente surge como uma questão a ser debatida no âmbito dessas elaborações sobre o desenvolvimento das nações.

No intento de buscar melhor compreensão acerca dos processos que envolvem desenvolvimento, crescimento econômico, desenvolvimento sustentável, pósdesenvolvimento, descolonialidade e questão ambiental é que o presente estudo foi elaborado.

Esse artigo é o documento final resultante de resumo e discussão apresentada no I Seminário Latino-americano de Estudos da Cultura É um estudo de caráter teórico, produzido a partir de revisão de literatura. É constituído por essa breve introdução, desenvolvimento, considerações finais e referencias.

\section{Antecedentes históricos: desenvolvimento como crescimento econômico e desenvolvimentismo na América Latina}

O contexto histórico em que emerge a noção de desenvolvimento se situa na 'reconstrução mundial', no período pós II Guerra Mundial, a partir de 1940, tanto como um processo de recuperação e de crescimento da economia em nível global, como uma ação contrária à expansão do bloco socialista em nível mundial. Tratava-se de recriar e refundar novas bases de acumulação, baseadas nos processos de redefinição da geopolítica mundial. 
O campo científico moderno da economia clássica e neoclássica ofereceu fundamentação teórica à interpretação desses processos de acumulação aos governos desses países. De acordo com Furtado(2009), os economistas clássicos (Smith, Ricardo, Stuart Mill) se preocuparam em compreender os processos de distribuição, baseados nos níveis de renda da terra e aumento dos salários, com relação à acumulação de capital. Dessa forma, o objeto central de análise se converteu na dinâmica do crescimento econômico, baseado na expansão da relação entre oferta, demanda, ou seja, na expansão dos mercados e do consumo, incorporando o progresso tecnológico (visão de Schumpeter) como interface significativa.

Como conceito engendrado na Europa ocidental desde os séculos XVIII e XIX, de acordo com Quintero (2013), o desenvolvimento representa uma ideia exclusiva da modernidade, sendo tanto um instrumento de classificação social, como fonte motivadora de forças sociais de tipos diversos, que atua com grande capacidade no mais profundo sentido da grande maioria da população do planeta.

Como conceito da modernidade, é apropriado e criado como crescimento econômico, um signo que cria, desenvolve e reproduz tanto em termos simbólicos como expresso em práticas sociais, uma metanarrativa econômica baseada em um eurocentrismo, tal como compreendido por Quijano(2005) $)^{2}$, que objetiva instituir os modelos de crescimento econômico e modos de vidas dos países do Norte como A referência mundial totalizante e globalizante a ser alcançada por todas as nações e habitantes do globo, desconsiderando e, ao mesmo tempo, invisibilizando possibilidade alternativas de existência de economias, culturas, políticas e modos de vida de outros países, nações e etnias, que não as eurocentradas.

O nome associado a essa perspectiva de desenvolvimento foi denominado nos países do Norte como Estado de Bem-estar social, assimilado como modelo teórico prático para a reconstrução de marcos de economia dentro desses países e, na sequência, como referência a ser alcançada pelos países do sul (GODOY, S.I.).

Uma perspectiva de desenvolvimento dada por etapas, nas quais, primeiramente os países mais avançados conseguiriam alcançar e, na sequência, os países do Sul também

\footnotetext{
${ }^{2}$ Nessa obra esse autor caracteriza a globalização como um processo culminante da constituição da América Latina, e do capitalismo/colonial/moderno/eurocêntrico, é entendida como um novo padrão de poder mundial, sustentado por classificações sociais baseadas em raças e no controle do trabalho. Um dos eixos fundamentais desse poder é a ideia de raça na classificação social da população mundial. Na perspectiva eurocêntrica, a relação social específica foi geograficamente concentrada na Europa, cujas raças, processos cognitivos, tecnológicos e territorialidades são consideras superiores à do Sul Global, por isso, dominantes e metas a serem alcançadas. O capitalismo mundial, desde o início foi colonial/moderno e eurocentrado, denominado sistemamundo, havendo uma sobrevalorização das populações e raças desses países da Europa, ou Norte Global e uma desvalorização social e de raças do povos dos países do Sul global, e é sobre essas qualificações e desqualificações que acumulação global dos sistema-mundo se sustenta.
} 
alcançariam, através da industrialização e da urbanização, o que eliminaria a pobreza e elevaria os níveis de consumo, a qualidade de vida e bem estar das populações dos países pobres.

Segundo Celso Furtado (2009, p. 161) “o advento do núcleo industrial da Europa passou a condicionar o desenvolvimento econômico subsequente em quase todas as regiões da Terra”. A acumulação dos países centrais incialmente aconteceu por meio da expansão geográfica, passando a basear-se na ampliação da produtividade social do trabalho, com estreita relação com a inovação e desenvolvimento tecnológico constante. A terceira via da expansão da economia europeia foi atingir regiões já ocupadas, sendo que "[...] a resultante foi quase sempre a criação de estruturas híbridas, uma parte tendendo a se comportar como sistema capitalista e outra mantendo-se dentro da estrutura pré-existente. [Tal fato] constitui especificamente o fenômeno do subdesenvolvimento contemporâneo" (FURTADO, 2009, p. 161).

A integração dos países subdesenvolvidos aos processos de acumulação global de acumulação de capital na era da modernidade, mesmo mediante processos de independência nacional, se deu, portanto, pela atualização e ressignificação de tradicionais formas de exploração dos países da periferia pelos países centrais. Constitui-se, dessa forma, uma relação de dependência entre centro e periferia, cujo pulso de acumulação global e do progresso parte dos países centrais e engloba os países da periferia, por meio da atualizando as condições de acumulação primitiva desses países, com vistas à manutenção da acumulação central global (PREBISCH apud COUTO, 2007; FURTADO, 2009).

Em um processo de divisão internacional do trabalho, as economias do centro se especializaram cada vez mais em ações de ampliação da produtividade social do trabalho, focadas no desenvolvimento tecnológico e na inovação, produção de meios de produção e de consumo industrializados, enquanto que as economias da periferia mantiveram-se acumulando mediante produção de baixa produtividade social do trabalho, baseadas na exportação de matérias primas, produtos agrícolas in natura, e na importação de bens de capital e de bens de consumo (FURTADO, 2009; PREBISCH apud COUTO, 2007).

Essa visão da acumulação de capital hegemônica desde os anos 1950 foi questionada por intelectuais, governos e organizações sociais da América Latina, tendo um de seus principais atores coletivos a CEPAL - Comissão Econômica para a América Latina e o Caribe. Através do pensamento dessa organização, notadamente do economista argentino Raul Prebisch, pode-se construir um corpo de pensamento e de ação sobre os processos de desenvolvimento da América Latina, que questionaram essa metanarrativa da acumulação dependente. 
Segundo Couto (2007, p. 47) "Prebisch criticava a postura dos Estados Unidos que ainda acreditavam que o livre funcionamento do mecanismo econômico corrigiria todos os males, sem a necessidade de uma política compensatória”. Além disso, também questionou a tese de que havendo redução dos preços dos produtos manufaturados no centro, pelo desenvolvimento tecnológico, os países da periferia seriam capazes de ampliar suas capacidades de compra desses produtos, sem necessidade de se industrializarem, tendo em vista que desde o final do século XIX os preços desse produtos primários vinham caindo.

Para Prebisch (apud Couto, 2007) essa economia neoclássica racionalizada e matematizada, mas cada vez mais distante da realidade política e econômica, seria incapaz de resolver os problemas que os países estavam passando a partir da crise de 1930.

Prebisch (apud Couto 2007, p. 50-51) compreendia que a deterioração dos termos de intercâmbio e o próprio processo de industrialização (que necessitava de importações) eram os motivos que levavam os países periféricos a desequilíbrios em seus balanços de pagamentos.

Dessa forma, há o questionamento dessa metanarrativa e a criação de modelos alternativos de desenvolvimento para a América Latina, desenvolvimentistas, baseados na proposta da substituição das importações, industrialização dos países periféricos e criação de um mercado interno. Esse deveria ser o caminho para o desenvolvimento, relativamente menos dependente para os países da América Latina.

Para Prebisch(apud Couto, 2007), o desenvolvimento econômico não viria de forma espontânea e sim de um esforço racional e deliberado, onde a acumulação de capital e a redistribuição da renda não se dariam pelo livre jogo do mercado, mas somente com uma grande participação do Estado sobre a poupança, a terra e a iniciativa individual, dando dinâmica ao sistema. Além disso, em um segundo momento, sendo também importante a manutenção e ajuste dos processos de exportação e de formação de um mercado latino americano, para aprofundamento do processo de substituição de importações, para a produção e consumo nesses países e mediante concorrência internacional de bens de produção.

Essas perspectivas desenvolvimentistas também se associaram a demandas sociais emergentes nesses contextos, apontadas por intelectuais, pela Cepal, e organizações sociais progressistas, que passaram a reivindicar reformas estruturais, seja como base para o avanço a processos socialistas, ou como bases reformistas para "destravar" a industrialização desses países, tais como reforma agrária, tributária, negociação de dívidas externas, criação de mercados comuns entre esses países (TAVARES, 1972.). 
Dos anos 1970 até os dias atuais, mediante ação de determinados Estados Nacionais, pode-se avançar em processos de industrialização nacional, substituição de importações e criação de mercados internos na maioria dos países subdesenvolvidos da América Latina, embora em condições diversas, heterogêneas e desiguais entre eles, e também na construção de alianças e de um mercado comum latino-americano, o Mercosul.

No entanto, a incapacidade de concorrência em nível internacional dos processos de industrialização dos países da América Latina; a insuficiente expansão dos mercados internos, a insuficiente capacidade de renda e de consumo das massas desses países; a presença de uma massa de trabalhadores com baixa qualificação técnica, associada à insuficiência de profissionais com qualificações técnicas; e a não realização de reformas estruturais foram interpretados por Tavares (1972) como argumentos constitutivos e limitantes desse modelo de substituição de importações.

Para essa autora (TAVARES, 1972), o declínio da dinâmica do modelo de substituição de importações é acompanhado pelo aprofundamento do mecanismo inflacionário como meio de acumulação, reforçando o traço atual característico da economia brasileira da acumulação financeira. Nesse interim, a abertura econômica do país a investimentos estrangeiros, bem como a ampliação dessa perspectiva de acumulação, retiraram do Estado e transferiram ao mercado e aos investidores estrangeiros a capacidade de regulação dos mercados e investimentos. Dessa forma, os centros de decisão desses países tem se tornado cada vez mais externalizados e alheios à capacidade de intervenções Estatais.

Nesse contexto de abertura a investimentos estrangeiros e financeirização, a América Latina nos anos 1990 é marcada pela emergência do neoliberalismo como opção de saída da crise de endividamento e de recessão vivenciada nos anos 1980. As características principais desse modelo neoliberal foram a manutenção dos endividamentos públicos desses países do sul, com relação ao países do norte; a abertura econômica das fronteiras dos países da América Latina para o comércio e investimento estrangeiro; a criação de acordos bilaterais de comercialização e tratados de livre comércio; a privatização de empresas e serviços públicos; a redução drástica do papel do Estado na gerencia e controle da economia; e a terceirização e flexibilização de legislações trabalhistas (BATISTA, 1994).

Ao longo dos anos 1990 essas economias se recuperaram a passos lentos e com fragilidades, porém, as consequências sociais foram agravadas, pois houve manutenção das desigualdades sociais e maior exclusão social, nas palavras de Batista (1994, p. 24):

“[...]Os resultados do neoliberalismo na América Latina, apesar dos esforços dos meios de comunicação em só mostrar os aspectos considerados positivos, não podem deixar de ser vistos como modestos, limitados que estão à 
estabilização monetária e ao equilíbrio fiscal. Miséria crescente, altas taxas de desemprego, tensão social e graves problemas que deixam perplexa a burocracia internacional baseada em Washington e angustiados seus seguidores latinoamericanos" (BATISTA, 1994, p 24).

Ocorrendo, portanto, um processo de atualização de formas colônias de controle e extração dos recursos desses países, sem que, ao mesmo tempo se pudesse avançar em processos distributivistas e equitativos de desenvolvimento. Sobre esses aspectos, Quijano (2014, p. 949) esclarece que:

“[...] de modo breve, se podría decir que en América Latina el resultado principal [da tentativa de desenvolvimento seguindo o modelo dos países do Norte] fue la remoción del 'Estado oligárquico' y de algunas de sus instancias en la existencia social de la población de estos países. Pero ni su dependencia histórico / estructural en la Colonialidad Global de Poder, ni los modos de explotación y de dominación inherentes a este patrón de poder, fueron erradicados o alterados suficientemente como para dar lugar a una producción y gestión democráticas del Estado, ni de los recursos de producción, ni de la distribución y apropiación del produto".

Quijano (2005), esclarece que essa colonialidade do poder se baseia no domínio do trabalho, das subjetividades e das identidades, cujos padrões são distribuídos globalmente e controlados desde os países do norte, centralmente Europa e Estados Unidos:

[...] la colonialidad del poder, tal y como ha sido conceptualizada por Aníbal Quijano (1992), se presenta como llave analítica que permite visualizar el inexorable espacio de confluencia entre la modernidad y el capitalismo, y el campo formado entre esta asociación estructural, en donde descansa-de diversas formas- el desarrollo. No es vano recordar que según Quijano (2000a y 2000b), la colonialidad constituye el patrón estructural de poder específico de la modernidad. Se compone históricamente a partir de la asociación entre un sistema de dominación asentado en un entramado de relaciones sociales intersubjetivas, basadas en la clasificación social jerárquica de la población mundial; y un sistema de explotación, que consiste en la articulación de todas las formas de control del trabajo conocidas en una única estructura hegemonizada por el capitalismo (QUINTERO, 2013, p. 69-70).

Nota-se, portanto, através da emergência do neoliberalismo na América Latina, a atualização de formas subalternas modernas-arcaicas de acumulação de capital, o que tem gerado como consequências, a manutenção da condição estrutural de concentração de riqueza, renda, desemprego, desigualdades sociais, econômicas, tecnológicas, políticas e culturais.

Mediante tais contextos, a emergência de processos democratizantes vivenciados na América Latina durante os anos 2000, com ênfase para os casos do Brasil, Equador, Bolívia e Venezuela, criaram situações de reintrodução da noção de Estado Nação de viés Keynesiano, como indutor, controlador e promotor do desenvolvimento, este, entendido não apenas como crescimento econômico, mas também como promoção social, reintroduzindo demandas da 
visão distributivista de desenvolvimento, presentes nos contextos da Cepal em idos dos anos 1970, pondo em cheque as perspectivas neoliberais em curso nesses países.

No caso do Brasil, durante os governos de Luís Inácio Lula da Silva, segundo Singer (2012) a situação favorável da economia mundial, a elevação dos preços das commodities, associadas ao incentivo interno do consumo, possibilitou a realização de medidas distributivistas por esses governos, tais como: acesso à educação básica, profissional e superior de classes sociais historicamente excluídas dos processos de ensino (FIES, cotas); acesso à casa própria por meio de programas de incentivo (Minha Casa Minha Vida); redução de índices de pobreza e desigualdades sociais, através de programas de distribuição de renda (Bolsa Família), mas principalmente através da geração de emprego e renda; além da redução da fome e situações de insegurança alimentar e nutricional (Programa Fome Zero); e de incentivos à inclusão produtiva, geração de micro e pequenos empreendimentos, economia solidária e agricultura familiar.

No entanto, Singer (2012), para o caso do Brasil e Gudynas(2012) para o caso da América latina, analisam que embora esses governos democráticos (Brasil, Venezuela, Bolívia, Equador) tenham sido fundamentais para a promoção de ações de redistribuição de renda e redução das desigualdades sociais, não foram/estão sendo capazes de erradicar problemas socioeconômicos e políticos crônicos presentes nessas sociedades latinoamericanas.

\section{Desenvolvimento sustentável, neoxtrativismo e a questão ambiental na América Latina contemporânea}

Até os anos 1970, nem a perspectiva neoclássica do crescimento a qualquer custo e nem mesmo a perspectiva desenvolvimentista da Cepal se questionavam sobre os limites biofísicos e ambientais do desenvolvimento. Se por um lado uma perspectiva estava focada em crescer a qualquer custo, a outra estava preocupada em crescer com distribuição de renda, riqueza e mais equidade nas relações entre países subdesenvolvidos e desenvolvidos, ou seja, transcender a condição histórica de dependência. Mas nenhuma delas procurou incorporar as dinâmicas ecológicas em suas análises e proposições socioeconômicas e políticas (SACHS, 2009).

No entanto, a partir da reconstrução do pós-guerra, em idos de 1970, se ultrapassou a capacidade de suporte/regulação do ambiente natural, estudos técnicos da área começam a 
demonstrar como esses eventos vinham ocorrendo, emergindo então um cenário de crise ambiental (LEFF, 2000).

A explosão da produção, do consumo de massas, notadamente do consumo dos países do norte, e da população mundial aparecem como os principais agentes causais e agravantes dessa crise ambiental (SACHS, 2009). Sendo “[...] uma crise que se manifesta pelo fracionamento do conhecimento e pela degradação do ambiente "(LEFF, 2000, p.19).

O crescimento, o desenvolvimento econômico e sua relação com o meio ambiente passam a ser questionados, tanto no âmbito da iniciativa privada, quanto dos Estados Nacionais, ONU e por meios sociais e acadêmicos científicos, constituindo-se em uma questão comum, entendida de diferentes formas por diversos agentes sociais (PIERRI,2002; GODOY, S.I.).

De bojo, abre-se um cenário propicio à construção de uma outra racionalidade, a ambiental, cuja complexidade dos problemas ambientais vivenciados vão demandar a construção da abordagens complexas no tratamento da questão ambiental em face aos planejamento de desenvolvimento (LEFF, 2000).

Nesse sentido, para além de respostas econômicas mecanicistas, tal como as sugeridas à perspectiva de desenvolvimento como crescimento econômico, o que se demanda nesse momento é a construção de um "[...] saber ambiental que se forja no encontro (enfrentamento, entrecruzamento, hibridação, antagosnismo) entre saberes diferenciados, por matrizes de racionalidade-identidade-sentido que respondem a estratégias de poder pela apropriação do mundo e da natureza" (LEFF, 2000, p. 46). Estimulando atores sociais diferenciados, movimentos sociais, intelectuais, governantes a pensarem outras perspectivas de desenvolvimento, capazes de internalizar a questão ambiental.

Mediante tal contexto, a ONU convocou a I Conferência Mundial sobre Meio Ambiente, para propor encaminhamentos, a qual ficou conhecida como conferência que Estocolmo de 1972. Nessa reunião ficou clara a polarização entre as noções de crescimento a qualquer custo e de crescimento zero. Nesse reunião, os países desenvolvidos do Norte propuseram medidas de decrescimento e redução do crescimento e consumo para o conjunto dos países presentes. No então, os países do Sul argumentavam que não poderiam deixar de consumir o que jamais chegaram a alcançar, e que precisariam primeiramente prover condições básicas de sobrevivência aos seus habitantes, sendo necessário, portanto, a manutenção de processos de crescimento econômico, pelo menos por esse período (GODOY, S.I). 
Segundo Godoy (S.I., p. 18), como alternativa à polarização entre as ideais de crescimento zero apresentada por países desenvolvidos e aquelas de crescimento a qualquer custo, defendida por alguns países do sul, foi proposto o conceito de ecodesenvolvimento.

Esse conceito foi elaborado teoricamente por Ignacy Sachs e fomentado em diversos eventos públicos, em que a questão ambiental passou a ser considerada como problema do desenvolvimento, no âmbito dos Estados Nação e das Nações Unidas.

Sachs em seu estudo Rumo à ecossocioeconomia: teoria e prática do desenvolvimento (2009), desenvolve uma crítica ao modelo hegemônico de produção e de consumo nas sociedades modernas, demonstrando como os países do norte, ao aderirem ao modelo do crescimento econômico, desenvolveram capacidade tecnológica e bem estar de seus habitantes, mas, ao mesmo tempo, constituíram-se com sociedades com modos de vida e de consumo degradantes e insustentáveis para a capacidade de resiliência e de suporte dos ecossistemas naturais do planeta, o que lhes torna incapazes de serem alcançados como modelos pelos países do Sul, não somente por critérios econômicos globais, mas pela insustentabilidade ecológica desses padrões de produção e de consumo que sustentam, demandando a todos busca pela construção de modelos de desenvolvimento alternativos, que sejam ao mesmo tempo produtivos e regeneradores das capacidades dos ecossistemas naturais e artificialmente produzidos.

Sachs esclarece que:

“[...] o crescimento é uma condição necessária, mas de maneira alguma suficiente para o desenvolvimento. Se for deixado à mercê das forças de mercado, pode estimular o mau desenvolvimento. Os padrões e propósitos dos crescimento devem subordinar-se ao tríplice critério de utilidade social, visibilidade econômica, e prudência ecológica". (SACHS, 2009, p.159).

Sachs(2009) elucida que, pelo fato dos países do Norte utilizarem a maior parte dos recursos naturais do planeta, cerca de $80 \%$, devem ser estes países os principais responsáveis pela mudança de padrões de produção consumo, indutores e fomentadores da criação de novas tecnologias, renováveis, auxiliando, inclusive os países do Sul global a se desenvolverem nessas novas bases.

Para Sachs(2009) cada região deve se desenvolver, a partir da valorização das suas capacidades e especificidades locais e territoriais, promovendo o emprego, saúde, educação, segurança, respeito às diversidades culturais, cuja exploração dos recursos naturais se dá em estreita solidariedade com as gerações futuras, substituindo a degradação pela recuperação das capacidades dos ecossistemas naturais e artificialmente produzidos. 
Para ele, “[...] o aperfeiçoamento de ecotécnicas é chamado a ocupar um lugar muito importante nas estratégias de desenvolvimento[...]" (SACHS, 2009, p.62) sendo capazes de: 1 - reduzir a exploração dos recursos naturais, principalmente daqueles poluentes - petróleo, etc.; 2 - reintroduzir eficientemente nos ciclos econômicos recursos já utilizados; 3 incentivar a produção e a conversão de biomassa; 4 - desenvolver tecnologias, máquinas, equipamentos, infraestruturas e usos de recursos naturais renováveis; 4 - reduzir o consumo, fundamentalmente dos países do norte; e 5 - sem degradar os ecossistemas, ampliar as capacidades de suporte e de resiliência destes e melhorar as condições de vida das populações dos países do Sul.

O ecodesenvolvimento, deve levar em consideração as cinco dimensões da sustentabilidade: 1 - sustentabilidade social - equidade e distribuição de rendas e riquezas; 2 sustentabilidade econômica - gerenciamento mais eficiente dos recursos e de um fluxo constante de investimentos públicos e privados; 3 - sustentabilidade ecológica - ampliar a capacidade de carga e de resiliência dos ecossistemas, limitar o consumo de combustíveis fósseis, reduzir poluição, intensificar pesquisa e desenvolvimento de tecnologias renováveis; 4 - sustentabilidade espacial - configuração rural-urbana mais equilibrada e melhor distribuída; 5 - sustentabilidade cultural - pluralidade de soluções, ajustadas às especificidades locais em cada contexto sócio-ecológico.

Em resumo o autor ponta que:

"[...] o ecodesenvolvimento é um estilo de desenvolvimento que, em cada região insiste na busca de soluções especificas para seus problemas particulares, levando em conta não só os dados ecológicos, mas também os culturais, bem como as necessidades imediatas e de longo prazo. Opera, portanto, com critérios de progresso relativizados a cada caso específico [...]. Sem negar a importância dos intercâmbios [...] o ecodesenvolvimento tenta reagir à moda predominante das soluções pretensamente universalistas e das fórmulas aplicáveis a qualquer situação. Em vez de atribuir uma importância excessiva à ajuda externa, confia na capacidade das sociedades humanas de identificar seus próprios problemas e apresentar soluções originais para os mesmos, ainda que se inspirando em experiências alheias" (SACHS, 2009, p. 64).

Nessa perspectiva do ecodesenvolvimento nota-se, portanto, a fusão entre demandas historicamente constitutivas de modelos alternativos de desenvolvimento, tais como aqueles propostos pela Cepal, de matriz Keynesiana, de caráter essencialmente socioeconômicos, com a introdução de aspectos da ecologia e da antropologia nas dinâmicas socioeconômicas, políticas e culturais do desenvolvimento.

No contexto da emergência desse estudo de Sachs, também os estudos de Amartya Sen(2010), entre outros, vão questionar não somente os pressupostos teóricos do desenvolvimento, mas também os primeiros estudos de indicadores de desenvolvimento 
produzidos pela ONU, os quais, baseados em uma visão de desenvolvimento como crescimento econômico, somente consideraram dados dos produtos nacionais internos e do PIB mundial como indicadores de desenvolvimento, apontando como necessidade a introdução de novos indicadores para o desenvolvimento dos países, tais como educação, saúde, alimentação, acesso a serviços, emprego e renda, sustentabilidade ecológica, entre outros.

Nessa arena de debates sobre o desenvolvimento, o conceito de ecodesenvolvimento foi internalizado pela ONU como desenvolvimento sustentável. Em 1987 há a produção pela ONU do documento intitulado Informe de Burthland. $\mathrm{O}$ documento parte da ideia central de que desenvolvimento e meio ambiente não podem ser separados. Esse documento incorpora essa noção de DESENVOLVIMENTO SUSTENTÁVEL como meta, saída e conciliação de interesses divergentes no âmbito da equalização dos termos entre desenvolvimento e meio ambiente (GODOY, p.20, S.I.).

Essa noção de desenvolvimento sustentável internalizada pela ONU e pactuada com os países membros, não deixou de incorporar a dimensão do crescimento econômico mas, ao mesmo tempo, passou a considerar a dimensão social, política, cultural e ecológica da sustentabilidade como critérios de promoção de processos de desenvolvimento das nações, em tese, ultrapassando a visão utilitarista e reducionista do desenvolvimento como crescimento econômico.

Também pode-se considerar que essa perspectiva de desenvolvimento sustentável da ONU inicialmente internalizou nos documentos firmados, a marca de um tênue questionamento ao modelo da colonialidade do poder, tal como compreendida por Quintero (2013), na medida em que suas metas integraram algumas noções distributivistas e ecológicas, tais como critérios sociais (redução da pobreza, acesso à educação), culturais (respeito às diversidades), políticos (democracia, cidadania) e ecológicos (adaptação, mitigação, resiliência).

Depois da Conferencia de Estocolmo, houveram outros eventos de pactuação de acordos sobre a questão do desenvolvimento e meio ambiente pelos Estados Nacionais, tais como Protocolo de Kyoto e agenda 21, buscando estabelecer acordos de redução da emissão de carbono; pactuação de investimentos no desenvolvimento de tecnologias com uso de recursos renováveis; conservação e recuperação de ecossistemas; mecanismos de aceleração de processos de recuperação e de conservação ambiental e acordos sobre usos da biodiversidade. 
No âmbito da questão ambiental, os acordos realizados na Rio 92, foram repactuados, porém, de forma menos compromissada nas reuniões e conferencias realizadas posteriormente, o que tem gerado certo vazio e descompromisso das Nações Unidas e Estados Nação presentes, sobre a necessidade de efetivação de marcos efetivos de desenvolvimento sustentável, sendo que a preocupação financeira das nações em manter suas economias em ordem se mantiveram à frente as discussões e pactuações efetivas (GUIMARÃES e FONTOURA, 2012).

De acordo com Porto-gonçalves (2017, p. 304): “em todos os fóruns internacionais onde se debate a questão ambiental, os anos 1990 marcam uma inflexão em direção à lógica mercantil, à lógica empresarial". Donde até os dias atuais, constata-se que a posição adotada pela ONU e assimilada pelos Estados Nação aderentes, tem optado cada vez mais por incentivar a capitalização dos recursos naturais, dotando-lhes de valor, outrora inexistentes, para tornar possível a aderência de empresas do setor privado à processos de conservação e recuperação ambiental, o que pode ser observado principalmente por meio da promoção do mercado de carbono, da fotossíntese e na troca de dívida externa por natureza.

Segundo Porto- Gonçalves(2017), o mercado passou a atuar como o agente principal de indução e de promoção da mudança de comportamento ambiental e de regulação dos usos da natureza e dos recursos naturais. A privatização, a capitalização dos recursos naturais e a internalização das externalidades ambientais por empreendimentos econômicos privados, são assumidos no âmbito da ONU como a saída possível para a problemática das mudanças climáticas e das questões ambientais em curso, tais como contaminações, desmatamentos, desgastes e erradicação de recursos não renováveis.

Os Estados Nação, em regime de "Estado mínimo" neoliberal longe de assumir qualquer posição de indução e controle, são chamados à se distanciar desses processos, atuando apenas como regulamentadores de tais transações privativas.

No entanto, Porto-gonçalves (2017) afirma que tal mecanismo de mercado tem se mostrado insuficiente, mediante quadros de agravamento dos processos de mudanças climáticas, bem como a partir da lenta concretude dos acordos internacionais firmados para redução das taxas de emissão de carbono e da conversão de matrizes tecnológicas de base renovável e sustentável.

Indicadores nos países do Sul são agravados pelo recrudescimento de processos de desmatamento, queimadas, poluição, desgaste de recursos naturais, tal como descrito no estudo de Porto, Pacheco e Leroy(2013), o que associado à commoditização e financeirização dessas economias, tem recriando nesses países um modelo neoextrativista de 
desenvolvimento, com base na exploração da mão-de-obra barata, na agricultura industrial de monocultivo intensivo e na mineração (GUDYNAS, 2012).

De acordo com Harvey(2004) os processos contemporâneos de acumulação indicam que a incapacidade de acumular através da reprodução ampliada sobre uma base sustentável, foi acompanhada por crescentes tentativas de acumular mediante a espoliação. Esta é a marca do que alguns denominam como o novo imperialismo.

Nesse novo imperialismo, o controle dos recursos dos territórios se tornam fundamentais, pois é através do controle desses recursos que o capital se realiza e se amplia, em estreita associação à financeirização das economias globais e nacionais. Esses processos acontecem por deslocalização e relocalização de capitais. As fronteiras e alocações dos investimentos se tornam mais fluídas, de acordo com as condições mais favoráveis nos diversos territórios (HARVEY, 2004).

Essa perspectiva é neoextrativista, pois atualiza e intensifica perspectivas extrativistas de acumulação de capital, um estilo de acumulação primitiva, que para o caso desses países do sul, jamais deixou de existir, atualizando-se, e intensificando-se nos atuais contextos de crise contemporânea de acumulação global de capital (BRANDÃO, 2010).

Para o Sul Global, as apostas desse modelo se concentram principalmente no controle e extração de recursos naturais e exploração de mão-de-obra barata, investindo-se principalmente em monocultivos de commodities e biotecnologias, por um lado, na extração de minérios e combustíveis fósseis, por outro (HARVEY, 2004).

Esse modelo de desenvolvimento neoextrativista adotado na América latina, tem aprofundado riscos, incertezas, injustiças e conflitos socioambientais, onde as disputas por território e recursos tornam-se objetos centrais desses conflitos, colocando, por um lado populações tradicionais, camponesas, moradores de periferias urbanas, que disputam não apenas territórios e recursos no sentido material e econômico do termo, mas colocam em ação a produção simbólica de si, de suas identidades e desses territórios vinculados, como tempoespaços da produção de estilos e modos de vida com saúde ambiental, e colocam por outro lado como responsáveis por esse conflitos, o próprio Estado, investidores, empresas mineradoras, especulação imobiliária, entre outros, que persistem degradando os recursos humanos e naturais dessas localidades (ACSELRAD, 2009; PORTO, PACHECO e LEROY, 2013).

Essa perspectiva econômico-política se constitui como hegemonia em ressonância com a colonialidade do poder, na medida em reproduz processos arcaicos de produção de desiguais de controle e acesso aos recursos naturais, ao trabalho, aos territórios, colocando em 
conflitos permanente populações originárias, indígenas, remanescentes de quilombos, camponeses, mulheres, moradores de áreas periféricas das cidades, trabalhadores, entre outros 'invisibilizados' em constante choque com esses forças de acumulação, concentração espoliação de capital (ACSELRAD, 2009; PORTO, PACHECO e LEROY, 2013).

É importante considerar, de acordo com Tavares que essa acumulação por espoliação possui uma dimensão financeira fundamental, aonde a acumulação por especulação ocupa local privilegiado (CUNHA, S.I.).

De acordo com Tavares (apud Cunha, S.I.), o acelerado processo de modernização ocasionado pela industrialização dos países da periferia no século XX, provocou um alto grau de heterogeneidade (não mais caracterizado em termos de dualismo) sem o entorpecimento da sua dinâmica. Nesse processo de modernização coexistem altas taxas de incorporação, expulsão e marginalização, e tais tendências não se revelaram contraditórias com a expansão. A financeirização dos países da periferia passa a constituir-se portanto, como um readaptação dessas economias às novas regras do jogo econômico-financeiro internacional.

Esse modelo de acumulação neoextrativista e financeirizado foi sendo assimilado por principalmente pelos países do Sul Global desde os anos 1980, como única possibilidade de alcançarem um "desenvolvimento sustentável”, o que na prática tem significado um modelo de desenvolvimento com poucas iniciativas na conservação dos recursos humanos e naturais e de insuficiente cumprimento das metas estabelecidas nos protocolos ambientais globais.

De acordo com Gudynas(2012), essa tem sido a posição das democracias ditas de esquerda da América Latina, tais como Bolívia, Brasil, as quais, não abdicando no modelo neoextrativista e financeirizado, tem justificado a continuidade desse modelo, com vistas à sustentação financeira de programas sociais de caráter distributivista, os quais lhes conferem legitimidade social e política.

É importante considerar que, embora hajam estreitos limites com relação às dinâmicas econômicas e ambientais dessas democracias, dadas suas fragilidades constitutivas como 'reformismos fracos' (Singer, 2012), o reconhecimento e a valorização das diversidades e identidades sócio-culturais dos povos da América Latina, de seus grupos étnicos nativos, mestiços, afrodescendente, constituem aspectos altamente relevantes dessas democracias, por atuarem diretamente na dissolução desses aspectos simbólicos da colonialidade do poder e do ser.

Nesse bojo, a questão ambiental continua a representar uma "questão ambiental". Pois longe de encontrar soluções rápidas, continua a figurar o cenário de inúmeros conflitos 
socioambientais e tem sido agravada nesses processos neoextrativistas, opção das economias latino-americanas.

\section{Outras alternativas de e ao desenvolvimento, Bem Viver e a questão ambiental}

Mediante tais contextos de crise econômica, social, ambiental, civilizatória, desde dos anos 1980, outras abordagens e perspectivas críticas tem surgido em nível global, se desenvolvendo e impactando principalmente em arenas e campos sociais e acadêmicos, através de para além da opção do desenvolvimento sustentável adotado pela ONU e pelos Estados Nação associados.

Essas outras/novas perspectivas tem buscado a construção social participativa de alternativas de e ao desenvolvimento, representando mudanças e continuidades, com relação às proposições outrora elencadas, tanto no âmbito do modelo distributivista, quanto da perspectiva do ecodesenvolvimento.

A primeira dessas abordagens, emergente ainda nos anos 1970, de caráter técnicocientífico, baseia-se na tese do decrescimento populacional e econômico zero, ou do decrescimento, “[...] sendo sua justificativa teórica mais clara aquela dada pela economia ecológica, principalmente através de um de seus fundadores, o economista norte-americano Herman Daly" (GODOY, S.I. p.19; PIERRI, 2002, p. 01-02).

A economia ecológica questiona a economia neoclássica e conceitua as relações econômicas como humanas e não-humanas em inter-relação e, adotando conceitos da ecologia, tais como entropia, busca internalizar na lógica econômica os usos e consumos de recursos naturais e de energia nos processos produtivos (DALY, 1991).

O decrescimento tem emergido como um conceito e como uma ação social, principalmente em países no Norte europeu, “[...] como um slogan político provocador, que visa principalmente enfatizar a importância de abandonar o objetivo de crescimento pelo crescimento, objetivo desprovido de sentido, cujas consequências são desastrosas para o meio ambiente" (LATOUCHE, 2012, p.45).

“O ponto de partida é uma mudança radical de valores em relação aos valores da sociedade de crescimento" (LATOUCHE, 2012, p. 49). Apontando para a redução da população, da produção e do consumo de massas, na adequação e adoção de modos de vida, na construção de circuitos curtos de economia, incentivo à produção de energias renováveis 
com foco no local e territorial e nas relações humanas, buscando "[...] trabalhar menos para viver melhor[...] para redescobrir o sentido da vida[...]" (LATOUCHE, 2012, p. 51).

Essa vertente emerge e encontra espaço-tempo para extensão principalmente nos países do Norte, notadamente Itália e França, na medida em que se ajusta às demandas apontadas pelo ecodesenvolvimento, de acordo como as concepções e indicações de Ignacy Sachs(2009) para esses países, principalmente em termos de redução da produção e do consumo, para ajuste e adaptação dessas economias a outros marcos socioeconômicos globais, ajustados às capacidades de suportes e resiliência dos ecossistemas globais.

No contexto dos países do Sul global, embora essa primeira vertente esteja também presente nos debates, ações sociais e pesquisas acadêmicas sobre meio ambiente, outras abordagens tem sido mais expressivas. Godoy (S.I) identifica outra vertente de alternativas de e ao desenvolvimento emergente desde os anos 1990 na América Latina, que seria o ecodesenvolvimento terceiro mundista, o qual "[...] propõe compatibilizar economia e ecologia mediante modos de existência alternativos" (GODOY, S.I, p. 19).

Essa vertente se aproxima e dialoga com o campo social e de estudos sociais contemporâneos denominados decolonial e pós-colonial. Para esse campo de estudos, cujos principais autores, poder-se-ia listar Boaventura Souza Santos, Enrique Dussel, Arturo Escobar, Eduardo Gudynas, Anibal Quijano e Pablo Quintero, a centralidade dos processos sociais emergentes e alternativos para a América Latina se situa na superação da condição de colonialidade do poder, do ser e do saber, como pressupostos para deixarmos de ser o que não somos e nos construirmos a partir de onde, de quem e do que somos, ao e a que desejemos nos tornar, em termos de sociabilidades e consumos, o que só pode ser alcançado a partir da construção de alternativas desde as territorialidades e dos sujeitos que vivem tais vidas e não a partir de modelos eurocentrados exógenos.

A partir dos estudos de Boaventura Souza Santos (2007 - entre outros), essas abordagens realizam uma crítica à espisteme moderna, questionando modelos prescritos de produção do conhecimento, abstratos e alheios às realidades sociais constitutiva de si, questionando a legitimidade da verdade científica como única possível, propondo a construção de uma ecologia de saberes (SANTOS, 2007), a qual, para além do conhecimento técnico-científico, busque-se a associação cognitiva com os processos de produção de conhecimento, de saberes, de sentidos, de significação do real não-científicos, a partir de modos, estilos e experiências de vida dos diversos grupos étnicos e povos da América Latina, África e Ásia, como meios para construção de interpretações possíveis dessas realidades, bem 
como para a produção compartilhada de alternativas ao desenvolvimento, transpondo modelos abstratos de desenvolvimento e de sociabilidade eurocentrados.

Na construção dessas novas perspectivas, a noção de território e territorialidade passa a ser fundamental. Os territórios e as territorialidades, tal como compreendidos por Pecquier (2005), são entendidos como relações, potenciais, potencialidades e capacidades endógenas, em constante construção e mediação com o global.

Há nessas perspectivas descoloniais, uma crítica tanto ao modelo hegemônico de desenvolvimento como crescimento a qualquer custo, quanto às perspectivas distributivistas, de caráter marxista e/ou keynesianos, tal como sinalizam Santos (2007) e Escobar(2014), na medida em que se compreende que ambas partem de uma epistemologia colonial eurocentrada, incapaz de produzir conhecimento real com as realidades e sujeitos locais e, por isso, incapaz de gerar soluções adaptadas e ajustadas à essas realidades.

Essa perspectiva epistêmica e cognitiva descolonial, baseada na ecologia de saberes, se dissocia de padrões epistêmicos e cognitivos abstratos, exógenos e eurocentrados, e se abre para buscar sentidos de si e para si DENTRO e COM e não FORA e PARA os humanos e não-humanos, através do entendimento das experiências vividas dos territórios e dos modos como vivenciam e significam suas existências e suas conexões entre humanos e nãohumanos, apostando em suas capacidades endógenas de criar e recriar realidades e sentidos de ser e de viver.

Associando-se a cosmovisões indígenas, ligadas ou não a abordagens marxistas contemporâneas, e também à perspectivas pós-modernas, esse campo intelectual e sóciopolítico parte da crítica de que "Si el desarrollo há logrado 'desarrollar' algo a lo largo de su historia, há sido la desigualdad y la assimetria em nível global, através del crecimiento e expansion del capitalismo y la colonialidad”. (QUINTERO, 2013, p. 74).

Nesse sentido, não há como pensar alternativas ao desenvolvimento que não sejam ao mesmo tempo pós-coloniais. Pois, para Quijano(2005), a descolonização da sociedade é pressuposição e ponto de partida para aprendermos a nos libertar do espelho eurocêntrico onde nossa imagem é sempre, necessariamente, distorcida, enfim de deixarmos de ser o que não somos.

Nesse campo teórico, o conceito de desenvolvimento é tomado por alguns autores, tais como Escobar e Acosta, como um conceito da modernidade e que obscurece qualquer possibilidade de se pensar outras formas de reprodução social, econômica, cultural, política, ecológica e ética nos países da América Latina. Para se pensar outras perspectivas de vida é 
preciso então despir-se desse conceito de uma vez por todas, buscando-se construir alternativas AO desenvolvimento (GUDYNAS, 2012; HIDALGO-CAPITÁN et..al., 2012).

Despir-se dessa perspectiva etnocêntrica do conceito do desenvolvimento é, ao mesmo tempo, se propor a construir uma nova perspectiva epistêmica cognitiva, uma ecologia de saberes(SANTOS, 2007), capaz de abrir mão da construção de modelos científicos e teóricos abstratos de desenvolvimento, para abrir-se para a comunicação e criação compartilhada de múltiplas respostas possíveis a problemas e realidades diversas, a partir das dinâmicas, dos territórios, dos saberes e dos olhares de quem ali habita, a partir das suas capacidades endógenas, cujo metabolismo social se processa cotidianamente, em mediação com a sociedade envolvente.

Donde saberes estigmatizados, invisibilizados, verdades não cientificizadas sejam acionadas, positivadas, e em associação a conhecimentos científicos, se possa buscar a criação de perspectivas cognitivas e epistêmicas, capazes de co-criar com nos territórios e com os sujeitos, humanos e não-humanos, para além de novos modelos generalistas e abstratos de desenvolvimento, novos estilos de sociabilidade e de sentido de existência entre humanos e não-humanos.

Nessa esteira, não haveria, portanto, um único e abstrato modelo de desenvolvimento ou mesmo de ecodesenvolvimento a ser alcançado, mas sim, múltiplas respostas possíveis e problemas socioambientais compartilhados, construídas desde as experiências e expertises locais dos sujeitos viventes em cada territorialidade, no sentido de estímulo e da promoção das múltiplas capacidades e potencialidades desses sujeitos e de suas territorialidades. As saídas possíveis para os problemas de aquecimento global, mudanças climáticas, 'pobreza', desigualdades, devem, portanto, provir a partir de quem, de onde e com quem se vive e vivencia tais situações.

Deslocar o olhar para os sujeitos não significa deixar de realizar mediações com a sociedade envolvente, e nem mesmo deixar de extrair dos conhecimentos científicos acumulados expressões uteis, no entanto, a natureza dessa mediação é que se altera substancialmente, de modo a permitir as aprendizagem colaborativas, bem como a reinvenção dessas realidades pelos sujeitos que as vivem tais quais, de forma que se constituam como o que são de modo positivado, deixando se ser ou de buscar ser o que não são, ou seja, de se espelhar nos filtros eurocêntricos de modelos, estilos, comportamentos de ser, ter e viver.

A noção de Bem Viver (BV) emerge no contexto desses debates pós coloniais nos países da América Latina, apontando perspectivas alternativas tanto de como ao 
desenvolvimento. Segundo Escobar (2012, p. 46) "[...] El BV "se presenta como una oportunidad para la construcción colectiva de una nueva forma de vida".

Em termos gerais, de acordo com a formulação de Hidalgo-Capitán et.al (2012, p, 20) a noção de Bem Viver significa vida em harmonia em três dimensões: consigo mesmo (pessoal), com a comunidade(social) e com a natureza(integral), nesse sentido, essa noção estaria vinculada aos conceitos de identidade, solidariedade e sustentabilidade.

Para Hidalgo-Capitán et. al. (2012), essa noção de bem viver se apresenta hoje com três vertentes distintas: a primeira delas é originária de indígenas e pachamamista, que fala do Sumak Kawsay, caracterizada pela relevância à autodeterminação dos povos indígenas e a reintrodução de elementos ético-morais e mágico-místicos à noção de bem viver. Cuja manifestação político-normativa pode ser internalizada na constituição Boliviana de 2009. Nas palavras de Gudynas (2011, p. 461):

"El intelectual aymara David Choquehuanca, actual ministro de relaciones exteriores de Bolivia, sostiene que el Vivir Bien es "recuperar la vivencia de nuestros pueblos, recuperar la Cultura de la Vida y recuperar nuestra vida en completa armonía y respeto mutuo con la madre naturaleza, con la Pachamama, donde todo es vida, donde todos somos uywas, criados de la naturaleza y del cosmos".

Essa abordagem do Bem Viver, visibiliza no âmbito do ordenamento jurídico desses países, a noção de sagrado da natureza e legitima a natureza - categoria não-humana - como sujeito portador de direitos, gerando, dessa forma, a demanda não somente pela construção de outro ordenamento jurídico, mas também pela construção de uma racionalidade ambiental, tal como compreendia por Leff (2000), “[...] que chama à construção de um saber fundado em uma constelação de diversidades arraigadas na cultura e na identidade" (LEFF, 2000 p.46).

Além disso, no âmbito da constituição de 2009 da Bolívia, a população desse país passou a ser proprietária dos seus recursos naturais, e não mais os Estados Nação, por isso, tornando-se responsável por esses, sendo sua responsabilidade conserva-los ou não para as gerações futuras.

Essa noção de Bem Viver, proveniente da cosmovisão indígena boliviana aponta para outra perspectiva de tratamento jurídico e político da problemática ambiental, a qual, para além do mercado ou do Estado - soluções apontadas pela ONU e Estados Nação até então (Porto-gonçalves, 2017) - coloca a população de cada país como responsável pela conservação de seus recursos naturais. 
A segunda vertente do Bem Viver, segundo Hidalgo-Capitán et. al. (2012) seria a corrente socialista e estatista, caracterizada pela relevância à gestão política estatal e à equidade social. Aspiram construir um bio-socialismo republicano ou bio-igualitarismo cidadão, a partir de planificação econômica participativa.

Essa vertente do Bem Viver se aproxima e traz consigo demandas inconclusas dos processos desenvolvimentistas na América Latina, resguarda sua significância por reintroduzir a necessidade da democratização, da erradicação da pobreza, da fome, das desigualdades sociais, econômicas e políticas, a promoção do emprego e da segurança, além do reconhecimento das diversidades culturais, estando presente na noção de Bem Viver, legitimada nas constituições tanto da Bolívia quanto do Equador. Para essa vertente, o desenvolvimento deve servir aos objetivos do Bem Viver, tal como definidos pelas diversidades de grupos étnicos indígenas presentes nesse país (GUDYNAS, 2011).

A terceira vertente do Bem Viver seria a corrente pós-desenvolvimentista e ecologista, caracterizada pela relevância que conferem à construção participativa do Bem Viver. Como uma colagem pós-moderna de concepções indígenas, camponesas, sindicalistas, cooperativistas, solidárias, feministas, pacifistas, ecologistas, descolonialistas, objetivam construir múltiplas sociedades que vivam cada uma sob um Bem Viver, cujo significado pode ser encontrado no interior de cada grupo (HIDALGO-CAPITÁN et. al., 2012).

Essa abordagem visa agregar e compatibilizar interesses coletivos convergentes, ainda que contraditórios, através da negociação, tal como manifesto nos Fóruns Sociais Mundiais, cujo caminhar desses possa lhes conduzir a produção de respostas múltiplas aos problemas ambientais e societários globais vivenciados na contemporaneidade, ajustadas às diversalidades de percepções e realidades, mediante possibilidades diversas de criação de alternativas não totalizantes, e sim abrindo-se para a construção pluridiversalidades constitutivas de mundos diversos, tal como indicado por Grósfoguel(2008).

Em resumo, o Bem viver, embora deva ser significado no interior de cada grupo social, pode-se dizer, grosso modo, que para o conjunto dessas vertentes parte de uma crítica ao modelo hegemônico de desenvolvimento, baseado do progresso e no crescimento e mesmo à perspectivas desenvolvimentistas englobantes e homogeneizadoras, demonstrando a insuficiência dessas perspectivas e mesmo do próprio conceito de desenvolvimento, na resolução de problemas enfrentamentos pelo povos da América Latina, constituindo-se como um chamamento à revisão e/ou à superação desse conceito. O que segundo Escobar(2012), mais do que uma alternativa de desenvolvimento pode significar uma alternativa ao desenvolvimento, na medida em que se avance ao um pós-desenvolvimento. 
Além disso, é mister acrescentar que, ao mesmo tempo em que se essas abordagens de Bem, Viver visam questionar, revisar e mesmo desconstruir o conceito de desenvolvimento, se aproximam de preceitos pós-coloniais, na medida em que apontam para a construção compartilhada desse Bem Viver, para uma ética intercultural, e para o reconhecimento das diversidades e heterogeneidades epistêmicas, étnicas, sexuais, etc., intervindo na superação da colonialidade do poder, do saber e do ser, como meios e fins para que se vivencie o Bem Viver.

No âmbito da questão ambiental, a inovação que se apresenta mediante essas diversas vertentes do Bem Viver é a introdução da legitimação de direitos constitucionais aos ditos recursos naturais, tais como água, solo, florestas e biodiversidade, deixando de ser considerados apenas como recursos produtivos, passando a ser considerados como sujeitos de direitos, tal como humanos (GUDYNAS, 2011).

Além disso, a introdução da noção de territorialidade, coloca a demanda pela construção endógena e relação ecológica de co-evolução entre humanos e não-humanos na construção de alternativas de e/ou al desenvolvimento para essas nações e povos, o que pode representar importantes avanços teórico-práticos na superação de visões de mundo e racionalidades utilitaristas no tratamento da questão ambiental, tanto em termos conceituais, rumo à construção de uma racionalidade ambiental, quanto em termos ecológicos, sociais, culturais, econômicos e políticos.

Em síntese, tanto a perspectiva do Bem Viver quanto a do decrescimento apresentam possibilidades econômicas e sócio-políticas de tratamento da questão ambiental, para além daquelas consideradas insuficientes até então adotadas pela ONU e Estados Nação.

\section{Considerações finais}

O modelo hegemônico de desenvolvimento como crescimento econômico e progresso tem sido questionado na América Latina, dada sua insuficiência na resolução da fome, pobreza, falta de segurança, emprego, renda, saúde, educação, conservação ambiental e bem estar desses povos.

Modelos alternativos distributivistas e baseados no discurso do desenvolvimento sustentável também tem se mostrado insuficientes na resolução de tais problemáticas, na justa medida em que reproduzem condições de colonialidade do poder, do ser e saber nesses países, além de recrudescer perspectivas financeirizadas e neoextrativistas nessas economias, ampliando contextos de conflitos e injustiças socioambientais. 
Alternativas recentes, ancoradas principalmente na perspectiva do Bem Viver podem apontar caminhos importantes na descolonialidade do poder, do ser e do saber, na medida em que visibilizam e que possibilitam a emergência de territorialidades, democracias baseadas em uma ética intercultural, capaz não somente de positivar humanos em suas múltiplas diversidades, mas também de instituir direitos constitucionais aos não-humanos, ou seja, à natureza, aos recursos naturais.

Por fim, compreende que se se faz necessário a continuidade de estudos teóricos e empíricos sobre as relações entre descolonialidade, territorialidade, bem viver e a relação com natureza, de forma que se possa melhor compreender as dinâmicas sociais em curso.

\section{Referencias}

ACSELRAD, H. O que é justiça ambiental. Rio de Janeiro: Garamond. 2009.

ALIER, J. M. Justiça Ambiental e decrescimento econômico a aliança dos dois movimentos. P. 55-78. In: LENA, P.; NASCIMENTO, E. P. (ORG). Enfrentando os limites do crescimento: sustentabilidade, decrescimento e prosperidade. RJ: Garamond. 2012.

BATISTA, P.N. O Consenso de Washington: A visão neoliberal dos problemas latinoamericanos. Cartilha da Consulta Popular. São Paulo. 1994.

BRANDÃO. C. R. Acumulação primitiva permanente e desenvolvimento capitalista no Brasil Contemporâneo. In: ALMEIDA, A. W. B. et. al. Capitalismo globalizado e recursos territoriais: fronteiras da acumulação no Brasil contemporâneo. Rio de Janeiro: Lamparina, 2010, p. 39-69.

COUTO. J. M. O pensamento desenvolvimentista de Raúl Prebisch. Economia e Sociedade, Campinas, v. 16, n. 1 (29), abr. 2007. p. 45-64.

DALY, H. A economia ecológica e o desenvolvimento sustentável. AS-PTA. Textos para debate. No 30. Rio de Janeiro, 1991.

ESCOBAR. A. Más allá del desarrollo: postdesarrollo y transiciones hacia el pluriverso. Revista de Antropología Social no 21, p. 23-62. 2012. 
ESCOBAR, A. Sentipensar con la tierra: nuevas lecturas sobre desarrollo, territorio y diferencia. Medellín. Colombia. Ediciones UNAULA. 2014.

FERNANDEZ, P.B. Ecodesenvolvimento, Desenvolvimento Sustentável e Economia Ecológica: em que sentido representam alternativas ao paradigma de desenvolvimento tradicional? Revista Desenvolvimento e Meio Ambiente, n. 23, p. 109-120, jan./jun. 2011.

FURTADO, C. Desenvolvimento e subdesenvolvimento. Editora Contraponto. 5ed. Rio de Janeiro. 2009.

GODOY, A.M.G. Padrão de desenvolvimento e meio ambiente. Paper. Universidade Federal do Paraná Programa de Pós-graduação em Meio Ambiente e Desenvolvimento. S.I.

GROSFOGUEL, R. Para descolonizar os estudos de economia política e os estudos póscoloniais: transmodernidade, pensamento de fronteira e colonialidade global. Revista Crítica de Ciências Sociais, 80, Março 2008.p. 115-147.

GUDYNAS, E. O novo extrativismo progressista na América do Sul: teses sobre um velho problema. Sob novas expressões. P.303-318. In: LENA, P.; NASCIMENTO, E. P. (ORG). Enfrentando os limites do crescimento: sustentabilidade, decrescimento e prosperidade. RJ: Garamond. 2012.

GUDYNAS, E. Buen Vivir: germinando alternativas ao desarollo. America Latina em Movimiento. ALAI. nº62. Febrero, Quito. 2011.

HARVEY. D. O Novo imperialismo. SOCIALIST. 2004. p.95-116.

HIDALGO-CAPITÁN, A. L. et. al. El Buen Vivir: la(re)creación del pensamento del Pydlos. Pydlos Ediciones. Cuenca. Ecuador. 2012.

LATOUCHE, S. O decrescimento. Por que e como? P. 45-54. In: LENA, P.; NASCIMENTO, E. P. (ORG). Enfrentando os limites do crescimento: sustentabilidade, decrescimento e prosperidade. Rio de Janeiro: Garamond. 2012. 
LEFF, Enrique, Complexidade, interdisciplinaridade e saber ambiental. In: A. Philippi Jr., C. E. M. Tucci, D. J. Hogan; R. Navegantes. (eds.) Interdisciplinaridade em Ciências Ambientais. São Paulo: Signus Editora, 2000, p. 19-51.

PECQUER, B. O desenvolvimento territorial: uma nova abordagem dos processos de desenvolvimento para as economias do sul. Raízes, Campina Grande, Vol. 24, nº 01 e 02, jan./dez. 2005. p. 10-22.

PIERRI, N. “Análisis crítico del instrumento de evaluacion de impacto ambiental. Su aplicación en Uruguai". Tese. Programa de Pós-Graduação em meio ambiente. UFPR. Curitiba. 2002.

PORTO, M. F.; PACHECO, T.; LEROY, J. P. (Orgs.). Injustiça ambiental e saúde no Brasil: o mapa de conflitos. Editora FIOCRUZ, 2013.

PORTO-GONÇALVES. C.W. A globalização da natureza e a natureza da globalização. Civilização Brasileira. Rio de Janeiro. 2017.

QUIJANO. A. ¿Bien vivir? Entre el «desarrollo» y la descolonialidad del poder En: Cuestiones y horizontes: de la dependencia histórico-estructural a la colonialidad/descolonialidad del poder. Buenos Aires: CLACSO, 2014.

QUINTERO, P. Desarrollo, modernidad y colonialidad. Revista de Antropología Experimental nº 13, Texto 5: 67-83. Universidad de Jaén (España). 2013.

SACHS. I.; VIEIRA.P.F (ORG). Rumo à ecossocioeconomia: teoria e prática do desenvolvimento. São Paulo. Cortez. 2009.

SANTOS. B. S. Para além do Pensamento Abissal: Das linhas globais a uma ecologia de saberes. Novos estud. - CEBRAP nº.79 São Paulo Nov. 2007.

SEN. A. Desenvolvimento como liberdade. São Paulo. Companhia das Letras. 2010. 
SINGER. A.V. Os sentidos do lulismo: reforma gradual e pacto conservador. 1 ed. — São Paulo. Companhia das Letras, 2012.

TAVARES. A. C. Da substituição de importações ao capitalismo financeiro. Zahar Editores. Rio de Janeiro. 1972. 